\title{
A Subjective Assessment of the Prevalence and Factors Associated with Poor Sleep Quality Amongst Elite Japanese Athletes
}

\author{
Masako Hoshikawa $^{1 *}$ (D), Sunao Uchida ${ }^{2}$ and Yuichi Hirano ${ }^{3}$
}

\begin{abstract}
Background: The amount, quality, and timing of sleep are considered important for athletes' ability to train, maximize training responses, and recover. However, some research has shown that elite athletes do not obtain sufficient sleep. Based on this background, researchers recently started to assess and manage sleep in elite athletes. The purpose of this study was to clarify the prevalence of poor sleep quality and its associated factors amongst elite Japanese athletes.
\end{abstract}

Methods: Eight hundred and ninety-one candidates for the 17th Asian Games Incheon 2014, who were over 20 years old, participated in this study. They completed a questionnaire that included the Pittsburgh Sleep Quality Index (PSQI), Epworth Sleepiness Scale, two-question case-finding instruments, and a checklist for sleep hygiene. Data from 817 of the 891 athletes (91.7\%) with no missing values were analyzed.

Results: The mean time in bed was $7 \mathrm{~h}$ and $29 \mathrm{~min}$. Two hundred and twenty-nine (28.0\%) athletes showed a PSQI global score above the clinical criteria. A multiple logistic analysis revealed that sleep quality was significantly associated with five factors: "time in bed," "eating breakfast every morning," "avoiding the use of electronic devices (PC, smartphone, etc.) just before bedtime," "depressive mood", and "not thinking about troubles while in bed." Forty percent of athletes reported they had been informed by someone about "snoring loudly" and/or "leg twitching or jerking during sleep."

Conclusions: The results of this study demonstrate that $28 \%$ of the athletes showed the PSQI score above the cutoff for poor sleep quality (>5.5), which suggests that there may be a high prevalence of poor sleep quality in this population of athletes. To improve athletes' sleep, the five factors associated with sleep quality should be emphasized in athletes' sleep education. Furthermore, in medical evaluations of athletes, it may be desirable to include screening for sleep disorders.

Keywords: Elite athletes, Sleep quality, Questionnaire study

\section{Key Points}

- Twenty-eight percent of elite Japanese athletes showed a PSQI global score above the cutoff for poor sleep quality.

- The PSQI global score above the cutoff for poor sleep quality was associated with five factors: "time in bed," "eating breakfast every morning," "avoiding the use of

\footnotetext{
*Correspondence: masako.hoshikawa@jpnsport.go.jp

${ }^{1}$ Department of Sport Research, Japan Institute of Sport Sciences, 3-15-1

Nishigaoka, Kita-ku, Tokyo 115-0056, Japan

Full list of author information is available at the end of the article
}

electronic devices (PC, smartphone, etc.) just before bedtime," "depressive mood," and "not thinking about troubles in bed."

- Forty percent of the athletes had been informed by someone about "snoring loudly" and/or "leg twitching or jerking during sleep."

\section{Background}

As represented by the Olympic motto "faster, higher, stronger," Olympic athletes must keep improving their athletic performance. To achieve this, they increase their frequency, volume, and intensity of training. Such an 
increase in the training load is often successful, and their performance improves. Since the training load will be compromised during periods of fatigue, fatigue management is very important for a successful increase in the load [1]. If athletes cannot maintain a favorable condition, it may be difficult to train as scheduled and to achieve good results.

Sleep is arguably one of the forms of recovery and regeneration available to elite athletes. The amount, quality, and timing of sleep are important for athletes' ability to train, maximize training responses, and recover. However, some research has shown that elite athletes do not obtain an adequate amount of sleep and that the prevalence of poor sleep quality is high $(>20 \%)$ [2-4]. Based on this background, researchers recently started to assess and manage sleep in elite athletes [3, 4].

The amount, quality, and timing of sleep in elite athletes may be affected by many factors, such as training-practice schedules [3, 4], training or exercise volumes [5-9], match schedules $[3,10,11]$, nervousness due to competitions [12-15], and sleep disorders [16-20]. Inappropriate sleep hygiene [21-25] is also known to influence the amount and quality of sleep; however, the present status of sleep hygiene in elite athletes has not been studied extensively.

Strictly speaking, factors that affect sleep quality may depend on the individual athletes. However, clarifying general factors correlated with sleep quality may be helpful for the sleep education of athletes.

The Pittsburgh Sleep Quality Index (PSQI) is a widely used standardized measure to assess subjective sleep quality [26]. The PSQI has been applied to both athletes and general populations. Fietze et al. reported that 12 of 24 German ballet dancers showed PSQI global scores above the cutoff level $(>5.5)$ [27]. In the Netherlands, Knufinke et al. reported that the mean PSQI global score in athletes was 4.61 and that 40 of 98 athletes showed a PSQI global score above the cutoff level [28]. In Japan, we studied 310 elite Japanese athletes and reported that the mean PSQI global score was 4.8, and 95 of the 310 athletes showed global scores above the cutoff level [29].

In this study, we defined sleep quality as being poor if the PSQI global score was above the cutoff level. A logistic regression analysis was performed to examine relevant factors, such as body mass index (BMI), some clinical information, mood, training-practice schedules, frequencies of overseas trips, sleep schedule, and sleep hygiene, and their association with poor sleep quality. The purpose of this study was to clarify the prevalence of poor sleep quality and its associated factors amongst elite Japanese athletes.

\section{Methods}

\section{Participants}

A total of 891 candidates for the 17th Asian games Incheon 2014, who were over 20 years old, participated in this study. The survey started on February 20 and ended on July 15, 2014. (The 17th Asian games Incheon 2014 was held between September 19 and October 4). Written informed consent was obtained after explaining the purpose, procedure, and possible risks of this study. This study was approved by the Japan Institute of Sports Sciences Ethics Committee.

Data from 817 (449 males and 368 females) of the 891 athletes $(91.7 \%)$ with no missing data were analyzed.

\section{Questionnaire}

The athletes were asked to complete the questionnaire after measuring their heights and weights. The questionnaire consisted of questions to obtain general information, the PSQI [30], the Epworth Sleepiness Scale (ESS) [31], two-question case-finding instruments [32], and a checklist for sleep hygiene. The general information included sex, age, sport, training-practice schedules, napping habits, and frequency of overseas trips in the past 6 months. Training-practice schedules were ascertained on each day of the week. Training-practice times per week were calculated from the training-practice times on each day.

The PSQI consists of 19 self-rated questions. The athletes were asked about their bed time, sleep latency, and getting-up time, and the time in bed and sleep efficiency were calculated as part of the PSQI. Subjective sleep quality was evaluated based on the global score of the PSQI. In the Japanese version, a PSQI global score higher than 5.5 is considered to indicate poor sleep quality [33]. The PSQI contains five other questions that are not reflected in the global score and are rated by a bed partner or roommate $[26,30]$. Since the athletes were not accompanied by a bed partner or roommate at the time of completing the questionnaire, the latter five questions were modified to be answered by the athletes themselves in this study as follows:

- Has any of your family, people living with you, or people who have stayed in the same room as you during a tour or other occasions made the following remarks to you?

(A) You snore loudly

(B) You take long pauses between breaths while asleep

(C) Your legs twitch or jerk while asleep

(D) You show episodes of disorientation or confusion during sleep

(E) You show other types of restlessness while asleep

For each of the five items, athletes selected an appropriate answer from the following: "Not at all," "Yes, sometimes," and "Yes, frequently." For the logistic regression analyses, "Yes, sometimes" and "Yes, frequently" were defined as "the athlete has the symptom." For the logistic regression analyses, "the athlete has the symptom" was 
assigned the dummy variable "1," and the absence of the symptom was assigned " 0. ."

Napping habits were clarified by asking three questions. Firstly, the athletes stated their frequency of napping by selecting one of five choices: no napping habits, less than once per week, 1-2 times per week, 3-5 times per week, and almost every day. Athletes with napping habits were requested to answer the second and third questions. In the second question, athletes stated their timing of starting to nap by selecting one of nine choices: before noon, eight time bands of every 1 hour from 12:00 to 19:00, and depends on case. Thirdly, athletes stated their duration of napping by selecting one of five choices: $30 \mathrm{~min}$ or less, 31 to $60 \mathrm{~min}, 61$ to $90 \mathrm{~min}$, more than $90 \mathrm{~min}$, and depends on case. For the logistic regression analyses, "no napping habit" and "within $30 \mathrm{~min}$ " were assigned the dummy variable "0," and the others were assigned "1."

Daytime sleepiness was evaluated by the ESS score (Japanese version). An ESS score higher than 10.5 is considered to indicate excessive daytime sleepiness [31].

Two-question case-finding instruments for depression were used to evaluate each athlete's mood [32]. The instruments consisted of two questions: (1) "During the past month, have you often been bothered by feeling down, depressed, or hopeless?" and (2) "During the past month, have you often been bothered by little interest or pleasure in doing things?" Athletes were requested to answer "yes" or "no" to each question. For Japanese adults, a sensitivity of $99 \%$ and a specificity of $60.5 \%$ have been reported if the respondent answers "yes" to either of the two questions. If the respondent answers "yes" to both questions, a sensitivity of $87.9 \%$ and a specificity of $81.4 \%$ have been reported [34]. For the logistic regression analyses, the answer "yes" to both questions was considered "the athlete feels a depressive mood." For the logistic regression analyses, "the athlete feels a depressive mood" was assigned the dummy variable " 1 ," and its absence was assigned " 0. "

Sleep hygiene was assessed using the modified checklist reported by Tamura and Tanaka [35].

Being bathed in sunlight after getting up

Eating breakfast every morning

Not taking a nap after 15:00

Not going out to bright places after 21:00

Avoiding the use of electronic devices just before bed time

Not drinking alcohol to induce sleep

Not thinking about troubles in bed

Keeping the bedroom quiet and comfortable

Using a comfortable mattress and bedclothing

Preventing an irregular getting up time (within $2 \mathrm{~h}$ )
Each question had three possible replies: "I already do so," "I may be able to, but do not already do so," and "I think it is difficult to do so." For the logistic regression analyses, "I may be able to, but do not already do so" and "I think it is difficult to do so" were defined as "the athlete does not already do so." For the logistic regression analyses, "the athlete does not already do so" was assigned the dummy variable " 1 ," and the other was assigned " 0. "

The athletes were asked about the frequency of overseas trips in the past 6 months.

The questionnaire took approximately $10 \mathrm{~min}$ to complete.

\section{Statistical Analysis}

For describing general information, data are expressed as the mean \pm SD. Statistical comparisons between sexes were conducted by the independent $t$ test for continuous variables and by chi-square tests and residual analyses for discrete variables.

In addition, the results of training-practice schedules, sleep schedule, the PSQI, the ESS, and clinical information were categorized within each variable, and then the number and percentages of athletes were described in the categories.

To explore factors associated with poor sleep quality (PSQI global score > 5.5), logistic regression analyses were performed using the following independent variables: age, sex, BMI, frequency of overseas expeditions, trainingpractice schedules, sleep schedules, clinical information, depressive mood, and sleep hygiene. Initially, we examined these variables using a univariate analysis. Then, a multiple logistic regression analysis was performed using the variables showing significant correlations in the univariate analysis $(p<0.05)$. For the continuous variables, the results were used for the logistic regression analyses. For the variables regarding clinical information, depressive mood, and sleep hygiene, dummy variables were used for the logistic regression analysis. Wald statistics were used to examine the significant odds ratios generated by the regression analyses. All analyses were performed using IBM SPSS 22 for windows. Significance was set at $p<0.05$.

\section{Results}

The athletes' heights, body weights, and BMIs were as follows: $177.5 \pm 8.7 \mathrm{~cm}, 76.7 \pm 12.9 \mathrm{~kg}$, and $24.2 \pm 3.0 \mathrm{~kg} /$ $\mathrm{m}^{2}$ for males, and $165.0 \pm 7.7 \mathrm{~cm}, 59.9 \pm 8.7 \mathrm{~kg}$, and 22.1 $\pm 2.6 \mathrm{~kg} / \mathrm{m}^{2}$ for females, respectively $(p<0.001)$. The BMIs in 296 males $(65.9 \%)$ were less than $25 \mathrm{~kg} / \mathrm{m}^{2}$, and those in 153 males (34.1\%) were equal to or greater than $25 \mathrm{~kg} / \mathrm{m}^{2}$. The indexes in 333 females (90.5\%) were less than $25 \mathrm{~kg} / \mathrm{m}^{2}$, and those in 35 females (9.5\%) were equal to or greater than $25 \mathrm{~kg} / \mathrm{m}^{2}$.

The characteristics of the athletes' daily schedules are presented in Table 1. If the athletes have several types of 
Table 1 The characteristics of daily schedules in elite Japanese athletes

\begin{tabular}{|c|c|c|c|c|c|}
\hline & & Male & & Fem & \\
\hline & & $N$ & $(\%)$ & $N$ & $(\%)$ \\
\hline Earliest training-practice & Before or at 7:00 & 68 & (15.5) & 60 & $(16.6)$ \\
\hline & 7:01-8:00 & 16 & (3.6) & 26 & $(7.2)$ \\
\hline & 8:01-9:00 & 121 & $(27.5)$ & 97 & $(26.9)$ \\
\hline & $9: 01-10: 00$ & 152 & (34.5) & 120 & $(33.2)$ \\
\hline & After 10:00 & 83 & $(18.9)$ & 58 & $(16.1)$ \\
\hline Latest training-practice & Before or at 18:00 & 261 & $(59.5)$ & 152 & $(42.2)$ \\
\hline & 18:01-19:00 & 47 & $(10.7)$ & 69 & $(19.2)$ \\
\hline & 19:01-20:00 & 47 & $(10.7)$ & 69 & $(19.2)$ \\
\hline & 20:01-21:00 & 68 & $(15.5)$ & 54 & $(15.0)$ \\
\hline & After 21:00 & 16 & (3.6) & 16 & $(4.4)$ \\
\hline $\begin{array}{l}\text { Hours of training-practice } \\
\text { per week }\end{array}$ & $\begin{array}{l}20 \mathrm{~h} \text { or less than } \\
20 \mathrm{~h}\end{array}$ & 190 & (43.6) & 144 & $(40.2)$ \\
\hline & $20.1-30 \mathrm{~h}$ & 164 & (37.6) & 130 & $(36.3)$ \\
\hline & $30.1-40 \mathrm{~h}$ & 66 & $(15.1)$ & 53 & $(14.8)$ \\
\hline & $40.1-50 \mathrm{~h}$ & 10 & $(2.3)$ & 18 & $(5.0)$ \\
\hline & More than $50 \mathrm{~h}$ & 6 & $(1.4)$ & 13 & (3.6) \\
\hline $\begin{array}{l}\text { Number of training-practice } \\
\text { session per week }\end{array}$ & $\begin{array}{l}1-5 \text { times per } \\
\text { week }\end{array}$ & 88 & (19.6) & 70 & $(19.0)$ \\
\hline & $\begin{array}{l}\text { 6-10 times per } \\
\text { week }\end{array}$ & 231 & $(51.4)$ & 177 & $(48.1)$ \\
\hline & $\begin{array}{l}\text { More than } 10 \\
\text { times per week }\end{array}$ & 130 & $(29.0)$ & 121 & $(32.9)$ \\
\hline Usual getting up time & Before or at $6: 00$ & 100 & $(22.3)$ & 103 & $(28.0)$ \\
\hline & $6: 01-7: 00$ & 191 & $(42.5)$ & 182 & $(49.5)$ \\
\hline & 7:01-8:00 & 118 & $(26.3)$ & 68 & $(18.5)$ \\
\hline & After 8:00 & 40 & $(8.9)$ & 15 & $(4.1)$ \\
\hline Usual time in bed & $<5 h$ & 4 & $(0.9)$ & 2 & $(0.5)$ \\
\hline & $\geqq 5$ and $<6 \mathrm{~h}$ & 7 & (1.6) & 21 & $(5.7)$ \\
\hline & $\geqq 6$ and $\leqq 7 \mathrm{~h}$ & 142 & (31.6) & 132 & $(35.9)$ \\
\hline & $>7$ and $\leqq 8 \mathrm{~h}$ & 186 & $(41.4)$ & 155 & $(42.1)$ \\
\hline & $>8 \mathrm{~h}$ & 110 & $(24.5)$ & 58 & $(15.8)$ \\
\hline Nocturnal sleep duration & $<5 \mathrm{~h}$ & 3 & $(0.7)$ & 7 & $(1.9)$ \\
\hline & $\geqq 5$ and $<6 \mathrm{~h}$ & 19 & $(4.2)$ & 36 & $(9.8)$ \\
\hline & $\geqq 6$ and $\leqq 7 \mathrm{~h}$ & 258 & $(57.5)$ & 225 & $(61.1)$ \\
\hline & $>7$ and $\leqq 8 \mathrm{~h}$ & 144 & $(32.1)$ & 90 & $(24.5)$ \\
\hline & $>8 \mathrm{~h}$ & 25 & (5.6) & 10 & $(2.7)$ \\
\hline Frequency of naps & No habit & 126 & $(28.1)$ & 89 & $(24.2)$ \\
\hline & $\begin{array}{l}\text { Less than once } \\
\text { per week }\end{array}$ & 59 & $(13.1)$ & 69 & $(18.8)$ \\
\hline & $\begin{array}{l}1-2 \text { times per } \\
\text { week }\end{array}$ & 99 & $(22.0)$ & 67 & $(18.2)$ \\
\hline & $\begin{array}{l}3-5 \text { times per } \\
\text { week }\end{array}$ & 118 & $(26.3)$ & 87 & (23.6) \\
\hline & Almost every day & 47 & $(10.5)$ & 56 & $(15.2)$ \\
\hline
\end{tabular}

Table 1 The characteristics of daily schedules in elite Japanese athletes (Continued)

\begin{tabular}{|c|c|c|c|c|c|}
\hline & & \multicolumn{2}{|c|}{ Male } & \multicolumn{2}{|c|}{ Female } \\
\hline & & $N$ & (\%) & $N$ & $(\%)$ \\
\hline \multirow[t]{5}{*}{ Nap duration } & $\leqq 30 \mathrm{~min}$ & 63 & $(14.0)$ & 53 & (14.4) \\
\hline & $31-60 \mathrm{~min}$ & 147 & $(32.7)$ & 134 & (36.4) \\
\hline & $61-90 \mathrm{~min}$ & 75 & $(16.7)$ & 50 & (13.6) \\
\hline & $\geqq 90 \min$ & 11 & $(2.4)$ & 13 & $(3.5)$ \\
\hline & Depends on case & 27 & (6.0) & 29 & (7.9) \\
\hline
\end{tabular}

training-practice schedules, the earliest start and latest end times were adopted as representative. The statistical analysis revealed significant differences between the sexes in the latest training-practice end time (18:20 \pm 2:00 for males and 18:36 \pm 2:00 for females, $p<0.01)$ and the hours of training-practice per week (22 h $30 \mathrm{~min} \pm$ $10 \mathrm{~h} 12 \mathrm{~min}$ for males and $24 \mathrm{~h} 36 \mathrm{~min} \pm 12 \mathrm{~h}$ for females, $p<0.05$ ), but not in the earliest trainingpractice start time $(9: 48 \pm 2: 42$ for males and 9:30 $\pm 2: 42$ for females). The mean time in bed was $7 \mathrm{~h}$ and $29 \mathrm{~min}$ in total: $7 \mathrm{~h}$ and $37 \mathrm{~min}$ for males and $7 \mathrm{~h}$ and $20 \mathrm{~min}$ for females $(p<0.001)$. Two point four percent of males and $6.3 \%$ of females were considered short sleepers (time in bed $<6 \mathrm{~h}$ ). For both males and females, more than half of the athletes have napping habits of once or more than once per week. Additionally, both males and females tend to prefer a nap duration of 31-60 min.

Table 2 describes the mean time in bed in athletes specialized in each sport. Each mean value was calculated when the values were obtained from more than four athletes. The results show a time in bed of less than $7 \mathrm{~h}$ in males from five sports and in females from nine sports.

The results of the PSQI and the ESS are presented in Table 3. Two-hundred and twenty-nine (28.0\%) athletes, 111 (24.7\%) males and 118 (32.1\%) females, showed a PSQI global score above 5.5. The mean and SD of the PSQI global scores were $4.2 \pm 2.1$ for males and $4.7 \pm 2.2$ for females $(p<0.01)$. The PSQI sub-category scores indicated the presence of $34(4.2 \%)$ athletes with a long sleep latency. The sub-category scores also indicated that $76(9.3 \%)$ athletes had difficulty maintaining their sleep. Fifty (11.1\%) males and 51 (13.9\%) females showed a sleep efficiency lower than $85 \%$. Two-hundred and sixtyfive (32.4\%) athletes, 112 (24.9\%) males and 153 (41.6\%) females, showed an ESS score above the cutoff level. The mean and SD of the ESS scores were $8.2 \pm 4.0$ for males and $9.7 \pm 4.1$ for females $(p<0.001)$. Overall, both the PSQI global and ESS scores were below the cutoff for 417 (51.0\%) athletes. For 91 (11.1\%) athletes, both scores were above the cutoff.

Regarding clinical information, approximately $40 \%$ of the athletes had been informed by someone about 
Table 2 The mean time in bed of athletes specialized in each sport

\begin{tabular}{|c|c|c|c|c|c|}
\hline & & Male & & Fem & \\
\hline & & $\mathrm{h}$ & (n) & $\mathrm{h}$ & $(n)$ \\
\hline Aquatics & Swimming & 6.9 & $(12)$ & 7.6 & $(12)$ \\
\hline & Diving & 7.0 & (4) & & \\
\hline & Synchronized swimming & & & 7.6 & $(11)$ \\
\hline & Water polo & 7.9 & $(15)$ & 7.1 & $(15)$ \\
\hline Archery & & 7.3 & (4) & 6.8 & (5) \\
\hline Athletics & & 7.5 & (33) & 7.4 & (26) \\
\hline Badminton & & 8.1 & $(11)$ & 8.0 & $(11)$ \\
\hline Baseball & Baseball & 7.7 & $(30)$ & & \\
\hline & Softball & & & 7.2 & $(16)$ \\
\hline Basketball & & 8.0 & $(20)$ & 7.6 & $(24)$ \\
\hline Bowling & & 7.5 & (5) & 6.9 & (5) \\
\hline Boxing & & 7.9 & (4) & & \\
\hline Canoe/kayak & Sprint & 7.8 & (9) & 8.6 & (4) \\
\hline & Obstacle slalom & 8.0 & (4) & & \\
\hline Cricket & & & & 6.7 & (13) \\
\hline Cycling & Track & 7.8 & $(11)$ & 7.9 & (8) \\
\hline & Road race & 8.5 & (5) & 7.6 & (6) \\
\hline & Mountain bike & & & & \\
\hline & Bicycle motocross & & & & \\
\hline Equestrian & & 7.4 & (8) & & \\
\hline Fencing & & 7.6 & (9) & 7.4 & (8) \\
\hline Football & & 8.1 & $(21)$ & 7.9 & (19) \\
\hline Golf & & 8.1 & (4) & & \\
\hline Gymnastics & Artistic & 8.3 & (4) & & \\
\hline & Rhythmic & & & & \\
\hline & Trampoline & 7.7 & (8) & & \\
\hline Handball & & 7.8 & $(22)$ & 7.6 & (19) \\
\hline Hockey & & 8.3 & $(25)$ & 7.2 & (18) \\
\hline Judo & & 7.0 & $(12)$ & 7.6 & (8) \\
\hline Kabaddi & & 6.3 & $(10)$ & 6.1 & (10) \\
\hline Karate & & 8.1 & (4) & 6.1 & (4) \\
\hline Modern pentathlon & & 7.7 & (9) & 7.6 & (6) \\
\hline Rowing & & 7.3 & $(15)$ & & \\
\hline Rugby & & 7.9 & (18) & 7.0 & (18) \\
\hline Sailing & & 7.9 & (6) & 8.5 & \\
\hline Sepaktakraw & & 7.0 & (13) & 6.4 & (9) \\
\hline Shooting & & 7.2 & (8) & 6.7 & $(11)$ \\
\hline Squash & & 6.3 & (2) & & \\
\hline Table tennis & & 7.3 & (4) & 7.7 & (7) \\
\hline Taekwondo & & 6.6 & (4) & & \\
\hline Tennis & Tennis & 8.1 & (5) & 7.9 & (5) \\
\hline & Soft tennis & 7.6 & (5) & 7.2 & (4) \\
\hline Triathlon & & 6.8 & (5) & 7.0 & (7) \\
\hline
\end{tabular}

Table 2 The mean time in bed of athletes specialized in each sport (Continued)

\begin{tabular}{|c|c|c|c|c|c|}
\hline & & Mal & & Fem & \\
\hline & & $\mathrm{h}$ & $(n)$ & $\mathrm{h}$ & $(n)$ \\
\hline Volleyball & Volleyball & 7.5 & (24) & 7.7 & (20) \\
\hline & Beach volleyball & & & & \\
\hline Weightlifting & & 7.3 & (7) & 6.7 & (6) \\
\hline Wrestling & & 7.4 & (13) & & \\
\hline Wushu & & 7.4 & (7) & 6.8 & (6) \\
\hline
\end{tabular}

"snoring loudly" and/or "leg twitching or jerking during sleep" (Table 4). Males were frequently described as loud snorers $(p<0.001)$ and taking long pauses between breaths $(p<0.01$, Table 4$)$. According to BMI, $4.7 \%$ of males and $1.2 \%$ of females in the categories with a BMI below $25 \mathrm{~kg} / \mathrm{m}^{2}$ had been informed of long pauses between breaths, whereas those values were 12.3 and $11.4 \%$ in the categories with a BMI at or above $25 \mathrm{~kg} /$ $\mathrm{m}^{2}$, respectively. Leg twitching or jerking during sleep was remarked in $55.5 \%$ of females $(p<0.01)$.

Regarding the results of the two-question case-finding instruments for depression, 141 (17.3\%) athletes in total, $58(12.9 \%)$ males and 83 (22.6\%) females, replied "yes" to both questions $(p<0.01)$.

The results of sleep hygiene are shown in Fig. 1. For both males and females, less than $20 \%$ of the athletes replied "I already do so" to the items "avoiding the use of electronic devices (PC, smartphone) just before bedtime" and/or "not thinking about troubles in bed."

Table 5 describes the results of the univariate and multiple logistic regression analyses. The univariate logistic regression analysis revealed that sex, bed time, time in bed, depressive mood, and eight of ten sleep hygiene-factors were significantly correlated with poor sleep quality (PSQI global score $>5.5$ ). In a multiple logistic regression analysis using the above variables, time in bed, depressive mood, and three sleep hygiene-factors were significantly correlated with poor sleep quality.

The results of the univariate and multiple logistic regression analyses for males and females are described in Tables 6 and 7. For males, time in bed, depressive mood, and the hygiene-factor "not thinking about troubles" were significantly correlated with poor sleep quality (Table 6). For females, getting up time, depressive mood, the hygiene-factors "not thinking about troubles in bed" and "preventing an irregular getting up time (within $2 \mathrm{~h}$ )" were significantly correlated with poor sleep quality (Table 7).

\section{Discussion}

The Prevalence and Factors Associated with Poor Sleep Quality

In the present study, we described the characteristics of the sleeping habits of elite Japanese athletes, investigated 
Table 3 Results of the Pittsburgh sleep quality index (PSQI) global and subcategories and Epworth Sleepiness Scale (ESS) scores

\begin{tabular}{|c|c|c|c|c|c|c|}
\hline & \multirow[b]{2}{*}{ Score } & \multicolumn{2}{|c|}{ Male } & \multicolumn{2}{|c|}{ Female } \\
\hline & & & $N$ & $(\%)$ & $N$ & $(\%)$ \\
\hline \multirow{2}{*}{\multicolumn{2}{|c|}{ PSQI-global score }} & $\leq 5.5$ & 338 & 75.3 & 250 & 67.9 \\
\hline & & $>5.5$ & 111 & 24.7 & 118 & 32.1 \\
\hline \multirow[t]{28}{*}{$\begin{array}{l}\text { PSQI-sub-category } \\
\text { score }\end{array}$} & $\begin{array}{l}\text { Self-rated sleep } \\
\text { quality }\end{array}$ & 0 & 50 & 11.1 & 40 & 10.9 \\
\hline & & 1 & 309 & 68.8 & 226 & 61.4 \\
\hline & & 2 & 87 & 19.4 & 100 & 27.2 \\
\hline & & 3 & 3 & 0.7 & 2 & 0.5 \\
\hline & Sleep latency & 0 & 146 & 32.5 & 127 & 34.5 \\
\hline & & 1 & 185 & 41.2 & 145 & 39.4 \\
\hline & & 2 & 100 & 22.3 & 80 & 21.7 \\
\hline & & 3 & 18 & 4.0 & 16 & 4.3 \\
\hline & Sleep duration & 0 & 169 & 37.6 & 100 & 27.2 \\
\hline & & 1 & 258 & 57.5 & 225 & 61.1 \\
\hline & & 2 & 19 & 4.2 & 36 & 9.8 \\
\hline & & 3 & 3 & 0.7 & 7 & 1.9 \\
\hline & Sleep efficiency & 0 & 399 & 88.9 & 317 & 86.1 \\
\hline & & 1 & 43 & 9.6 & 42 & 11.4 \\
\hline & & 2 & 5 & 1.1 & 7 & 1.9 \\
\hline & & 3 & 2 & 0.4 & 2 & 0.5 \\
\hline & Sleep disturbance & 0 & 163 & 36.3 & 108 & 29.3 \\
\hline & & 1 & 283 & 63.0 & 254 & 69.0 \\
\hline & & 2 & 3 & 0.7 & 6 & 1.6 \\
\hline & & 3 & 0 & 0.0 & 0 & 0.0 \\
\hline & Use of sleeping meds & 0 & 434 & 96.7 & 362 & 98.4 \\
\hline & & 1 & 10 & 2.2 & 4 & 1.1 \\
\hline & & 2 & 1 & 0.2 & 1 & 0.3 \\
\hline & & 3 & 4 & 0.9 & 1 & 0.3 \\
\hline & Daytime dysfunction & 0 & 254 & 56.6 & 170 & 46.2 \\
\hline & & 1 & 154 & 34.3 & 162 & 44.0 \\
\hline & & 2 & 33 & 7.3 & 33 & 9.0 \\
\hline & & 3 & 8 & 1.8 & 3 & 0.8 \\
\hline \multirow[t]{2}{*}{ ESS-score } & & $\leq 10.5$ & 337 & 75.1 & 215 & 58.4 \\
\hline & & $>10.5$ & 112 & 24.9 & 153 & 41.6 \\
\hline
\end{tabular}

the prevalence of poor sleep quality on the PSQI global score, and explored its associated factors. Based on our knowledge, this is the first study to examine a large number of elite athletes $(n=817)$.

Our results using the PSQI global score indicated that sleep quality is poor in $28 \%$ of elite Japanese athletes. A previous study [36] that examined general populations in Japan reported that the PSQI global scores were 4.51 \pm 2.14 for males in their $20 \mathrm{~s}$ and $5.30 \pm 2.48$ for females in their 20s. This study also reported that $30.1 \%$ of
Table 4 The frequency and distribution of responses to clinical questions

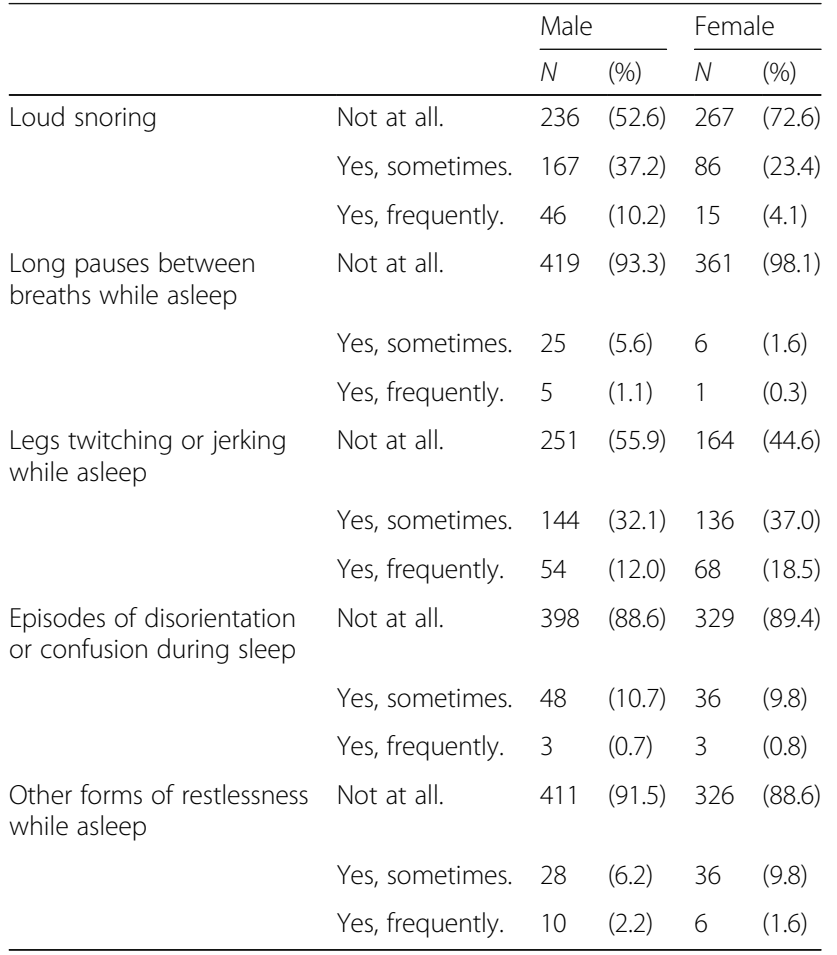

males in their 20 s and $36.4 \%$ for females in their 20 s scored above the cutoff for poor sleep quality on the PSQI. Our results of the mean PSQI global scores and prevalence of poor sleep quality for both males and females were slightly better than those of age-matched general populations in Japan. The differences between sexes observed in the sleep schedules, PSQI global, and ESS scores in this study were in line with those in previous studies [36, 37].

The multiple logistic analysis revealed that athletes' sleep quality was significantly associated with five factors: "time in bed," "depressive mood," "eating breakfast every morning," "avoiding the use of electronic devices (PC, smartphone) just before bedtime," and "not thinking about troubles in bed." Regarding excessive daytime sleepiness, Doi and Minowa examined 4722 Japanese and reported that insufficient nocturnal sleep, an irregular sleep-wake schedule, and depression were associated risk factors [37]. Although the evaluated parameters differed between the latter research and ours (PSQI global and ESS scores), common backgroundrelated factors may exist.

\section{Time in Bed}

Our study shows that the mean time in bed was $7 \mathrm{~h}$ and $29 \mathrm{~min}$ in total, corresponding to $7 \mathrm{~h}$ and $37 \mathrm{~min}$ for males and $7 \mathrm{~h}$ and $20 \mathrm{~min}$ for females. As shown in Table 2 , males from five sports and females from nine sports 


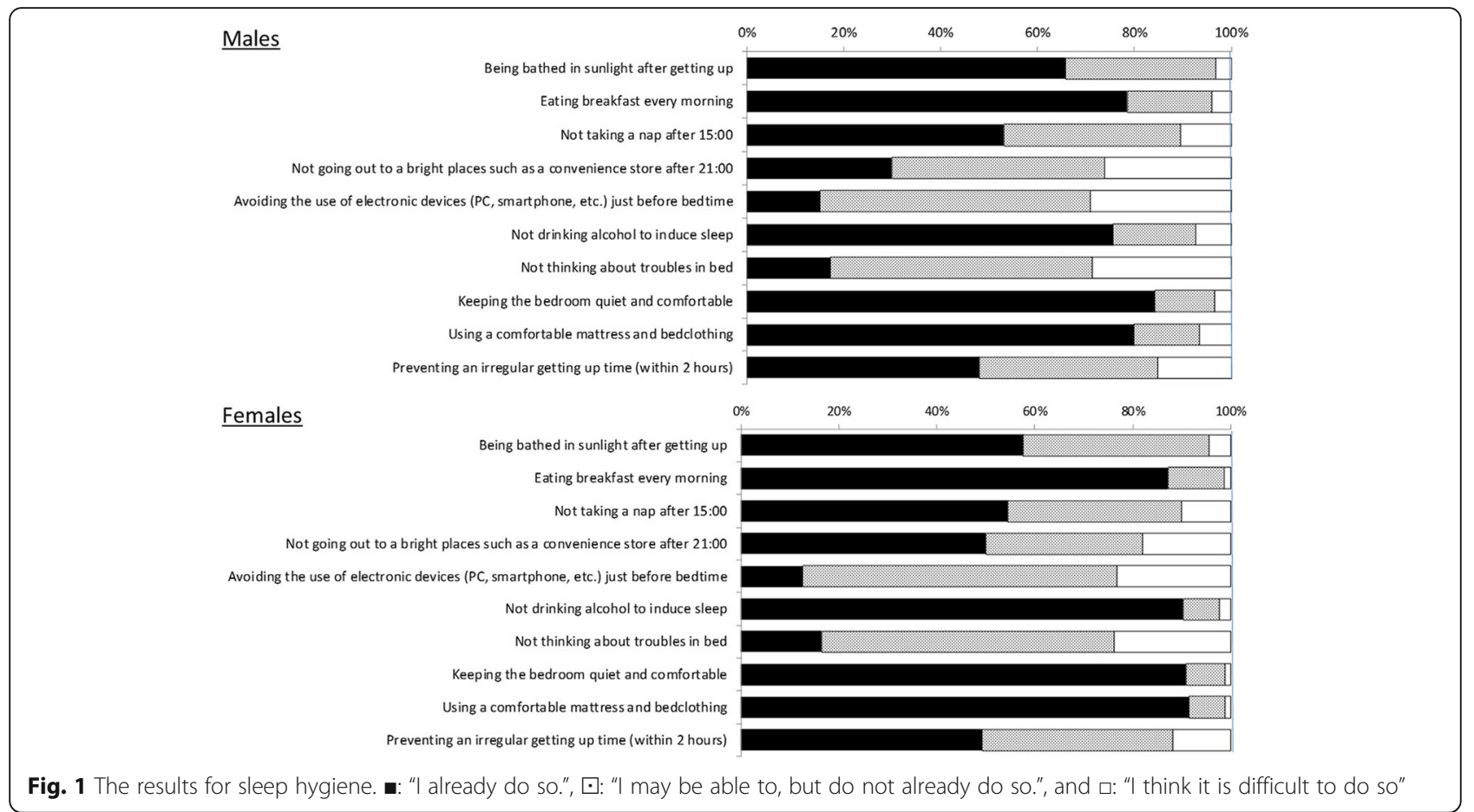

showed a mean time in bed of less than $7 \mathrm{~h}$. The 2015 NHK Japanese Time Use Survey revealed that the sleep duration was $7 \mathrm{~h}$ and $27 \mathrm{~min}$ for males in their $20 \mathrm{~s}$ $(n=424)$ and $7 \mathrm{~h}$ and $18 \mathrm{~min}$ for females in their $20 \mathrm{~s}$ $(n=437)$ [38]. Since sleep duration is generally shorter than time in bed, our results may suggest that time in bed of Japanese athletes was not as long as those of age-matched general populations. At present, it is unclear and debatable whether a time in bed that is the same as the general population is sufficient for athletes. However, some researchers recommend a longer nocturnal sleep, i.e., 8-10 h [39-41] for athletes. Samuels and Alexander [40] recommend $8-10 \mathrm{~h}$ of nocturnal sleep plus a 30-min nap between 2 and $4 \mathrm{pm}$ for athletes. Bompa and Haff [41] reported that athletes require 9 to $10 \mathrm{~h}$ of sleep, $80-90 \%$ of it during the night. Rountree [42] recommends sleep extension with a longer training-practice time. Our results suggest that the time in bed of elite Japanese athletes is inconsistent with their recommendations.

Our study revealed that $34(4.2 \%)$ athletes were considered short sleepers (time in bed $<6 \mathrm{~h}$ ). Seventeen of the 34 short sleepers get up earlier than 6:00. However, only 4 of the 17 short sleepers reported that their training-practice starts before 8:00. Sargent et al. [4] reported that early-morning training markedly restricts the time in bed of swimmers. Our results differ from theirs. For an example, all of our kabaddi players reported that their training-practice starts around 19:00 and ends at 21:00. Twelve of 20 kabaddi players get up at 7:00 or earlier because of their jobs. For them, the schedules of both training-practice and their job may be the reasons for their short time in bed.

\section{Use of Electronic Devices}

In this study, more than $80 \%$ of the athletes replied that they use electronic devices (PC, smartphone) just before bedtime. The Ministry of Posts and Telecommunications (Japan) reported that $53.7 \%$ of Internet users in Japan had delayed bedtimes, and $45.4 \%$ of them had a shortened sleep duration as a result of internet use [43]. It is also known that lights from electronic devices reduce melatonin levels, increase alertness at night, delay the circadian clock, and decrease alertness the next morning [22]. Thus, using electronic devices just before bedtime may lead to a shortened sleep duration and poor sleep quality [23-25].

\section{Skipping Breakfast}

It is already known that skipping breakfast is associated with poor sleep quality [44]. Previous researchers have stated that busy lifestyles cause some people to skip breakfast, but some also suggested that skipping breakfast affects circadian rhythms. For example, in the liver, breakfast promotes food-induced entrainment of the circadian clock [45]. In addition, some researchers suggest that dietary components influence the synthesis of serotonin and melatonin, and this contributes to a 
Table 5 The associations amongst sex, age, body mass index, experience of overseas trips, training-practice schedule, depressive mood and sleep habits, and poor sleep quality (PSQI global score > 5.5)

\begin{tabular}{|c|c|c|c|c|c|c|c|}
\hline & & $\beta$ & SE & Wald-square & Odds & $95 \% \mathrm{Cl}$ & $P$ value \\
\hline \multicolumn{8}{|c|}{ (A) Univariate logistic regression analysis } \\
\hline \multirow[t]{4}{*}{ General information } & Sex & -0.336 & 0.157 & 4.578 & 0.715 & $0.525-0.972$ & $<0.05$ \\
\hline & Age & 0.003 & 0.017 & 0.029 & 1.003 & 0969-1.038 & 0.86 \\
\hline & Body mass index & 0.138 & 0.190 & 0.528 & 1.148 & $0.791-1.666$ & 0.47 \\
\hline & Frequency of overseas trips & -0.040 & 0.035 & 1.314 & 0.961 & $0.897-1.029$ & 0.25 \\
\hline \multirow[t]{7}{*}{ Daily schedule } & Earliest training-practice start time & 0.028 & 0.030 & 0.894 & 1.029 & $0.970-1.091$ & 0.34 \\
\hline & Latest training-practice end time & -0.055 & 0.039 & 1.952 & 0.947 & $0.877-1.022$ & 0.16 \\
\hline & Hours of training-practice per week & -0.006 & 0.007 & 0.780 & 0.994 & $0.980-1.008$ & 0.38 \\
\hline & Bed time & -0.222 & 0.083 & 7.200 & 0.801 & $0.682-0.942$ & $<0.01$ \\
\hline & Getting up time & 0.123 & 0.078 & 2.474 & 1.131 & $0.970-1.319$ & 0.12 \\
\hline & Time in bed & -0.357 & 0.081 & 19.586 & 0.700 & $0.598-0.820$ & $<0.001$ \\
\hline & Nap duration & 0.161 & 0.159 & 1.025 & 1.175 & $0.860-1.604$ & 0.31 \\
\hline \multirow[t]{4}{*}{ Clinical information } & Loud snoring & 0.105 & 0.122 & 0.743 & 1.111 & $0.874-1.412$ & 0.39 \\
\hline & Sleep apnea & 0.044 & 0.246 & 0.032 & 1.045 & $0.645-1.693$ & 0.86 \\
\hline & Legs twitching or jerking during sleep & -0.183 & 0.103 & 3.151 & 0.833 & $0.680-1.019$ & 0.08 \\
\hline & Disorientation or confusion during sleep & -0.215 & 0.186 & 1.341 & 0.806 & $0.560-1.161$ & 0.25 \\
\hline Mood & Depressive mood & -1.363 & 0.194 & 49.569 & 0.256 & $0.175-0.374$ & $<0.001$ \\
\hline \multirow[t]{10}{*}{ Sleep hygiene } & Being bathed in sunlight after getting up & -0.318 & 0.161 & 3.876 & 0.728 & $0.530-0.999$ & $<0.05$ \\
\hline & Eating breakfast every morning & -0.763 & 0.194 & 15.395 & 0.466 & $0.319-0.683$ & $<0.001$ \\
\hline & Not taking a nap after 15:00 & -0.224 & 0.159 & 1.984 & 0.799 & $0.585-1.092$ & 0.16 \\
\hline & Not going out to bright places after 21:00 & -0.150 & 0.164 & 0.831 & 0.861 & $0.624-1.188$ & 0.36 \\
\hline & Avoid using electronic devices just before bed time & -0.833 & 0.285 & 8.580 & 0.435 & $0.249-0.759$ & $<0.01$ \\
\hline & Not drinking alcohol to induce sleep & -0.462 & 0.197 & 5.506 & 0.630 & $0.429-0.927$ & $<0.05$ \\
\hline & Not thinking about troubles in bed & 1.066 & 0.166 & 41.021 & 2.903 & $2.095-4.023$ & $<0.001$ \\
\hline & Keeping the bedroom quiet and comfortable & -0.645 & 0.222 & 8.423 & 0.525 & $0.339-0.811$ & $<0.01$ \\
\hline & Using a comfortable mattress and bedclothing & 0.569 & 0.166 & 11.726 & 1.766 & $1.275-2.445$ & $<0.001$ \\
\hline & Preventing an irregular getting up time (within $2 \mathrm{~h}$ ) & -0.614 & 0.163 & 14.276 & 0.541 & $0.392-0.744$ & $<0.001$ \\
\hline \multicolumn{8}{|c|}{ (B) Multiple logistic regression analysis } \\
\hline General information & Sex & -0.147 & 0.188 & 0.608 & 0.863 & $0.597-1.368$ & 0.44 \\
\hline \multirow[t]{2}{*}{ Daily schedule } & Bed time & 0.099 & 0.109 & 0.823 & 1.104 & $0.891-1.368$ & 0.36 \\
\hline & Time in bed & 0.401 & 0.106 & 14.319 & 1.494 & $1.213-1.839$ & $<0.001$ \\
\hline Mood & Depressive mood & -1.170 & 0.212 & 30.496 & 0.310 & $0.205-0.470$ & $<0.001$ \\
\hline \multirow[t]{8}{*}{ Sleep hygiene } & Being bathed in sunlight after getting up & -0.166 & 0.185 & 0.802 & 0.847 & $0.589-1.218$ & 0.37 \\
\hline & Eating breakfast every morning & -0.593 & 0.225 & 6.955 & 0.552 & $0.355-0.859$ & $<0.01$ \\
\hline & Avoid using electronic devices just before bed time & -0.625 & 0.313 & 3.989 & 0.535 & $0.290-0.988$ & $<0.05$ \\
\hline & Not drinking alcohol to induce sleep & -0.174 & 0.224 & 0.606 & 0.840 & $0.541-1.303$ & 0.44 \\
\hline & Not thinking about troubles in bed & -0.759 & 0.184 & 16.962 & 0.468 & $0.326-0.672$ & $<0.001$ \\
\hline & Keeping the bedroom quiet and comfortable & -0.312 & 0.254 & 1.510 & 0.732 & $0.445-1.204$ & 0.22 \\
\hline & Using a comfortable mattress and bedclothing & -0.214 & 0.192 & 1.248 & 0.807 & $0.554-1.176$ & 0.26 \\
\hline & Preventing an irregular getting up time (within $2 \mathrm{~h}$ ) & -0.328 & 0.184 & 3.182 & 0.720 & $0.503-1.033$ & 0.07 \\
\hline
\end{tabular}


Table 6 The associations amongst sex, age, body mass index, experience of overseas trips, training-practice schedule, depressive mood and sleep habits, and poor sleep quality (PSQI global score > 5.5) in males

\begin{tabular}{|c|c|c|c|c|c|c|c|}
\hline \multirow{2}{*}{\multicolumn{8}{|c|}{ (A) Univariate logistic regression analysis }} \\
\hline & & & & & & & \\
\hline \multirow[t]{3}{*}{ General information } & Age & -0.028 & 0.027 & 1.090 & 0.972 & $0.922-1.025$ & 0.296 \\
\hline & Body mass index & 0.006 & 0.037 & 0.024 & 1.006 & $0.935-1.081$ & 0.878 \\
\hline & Frequency of overseas trips & 0.029 & 0.047 & 0.381 & 1.029 & $0.939-1.129$ & 0.537 \\
\hline \multirow[t]{7}{*}{ Daily schedule } & Earliest training-practice start time & 0.000 & 0.040 & 0.000 & 0.995 & $0.925-1.082$ & 0.995 \\
\hline & Latest training-practice end time & 0.062 & 0.055 & 1.265 & 1.064 & $0.955-1.186$ & 0.261 \\
\hline & Hours of training-practice per week & 0.003 & 0.011 & 0.055 & 1.003 & $0.982-1.024$ & 0.814 \\
\hline & Bed time & 0.260 & 0.112 & 5.394 & 1.297 & $1.041-1.614$ & 0.020 \\
\hline & Getting up time & 0.027 & 0.103 & 0.067 & 1.027 & $0.840-1.255$ & 0.796 \\
\hline & Time in bed & -0.294 & 0.110 & 7.132 & 0.745 & $0.601-0.925$ & 0.008 \\
\hline & Nap duration & -0.039 & 0.220 & 0.031 & 0.962 & $0.625-1.482$ & 0.861 \\
\hline \multirow[t]{4}{*}{ Clinical information } & Loud snoring & -0.032 & 0.219 & 0.021 & 0.969 & $0.631-1.489$ & 0.886 \\
\hline & Sleep apnea & -0.291 & 0.470 & 0.383 & 0.748 & $0.298-1.879$ & 0.536 \\
\hline & Legs twitching or jerking during sleep & 0.292 & 0.219 & 1.772 & 1.339 & $0.871-2.059$ & 0.183 \\
\hline & Disorientation or confusion during sleep & 0.271 & 0.329 & 0.677 & 1.311 & $0.688-2.497$ & 0.411 \\
\hline Mood & Depressive mood & 1.667 & 0.294 & 32.198 & 5.297 & $2.976-9.421$ & 0.000 \\
\hline \multirow[t]{10}{*}{ Sleep hygiene } & Being bathed in sunlight after getting up & 0.430 & 0.224 & 3.695 & 1.537 & $0.992-2.384$ & 0.055 \\
\hline & Eating breakfast every morning & 0.851 & 0.241 & 12.761 & 2.366 & $1.475-3.796$ & 0.000 \\
\hline & Not taking a nap after 15:00 & 0.173 & 0.219 & 0.621 & 1.188 & $0.774-1.825$ & 0.431 \\
\hline & Not going out to bright places after 21:00 & 0.518 & 0.259 & 4.019 & 1.679 & $1.012-2.787$ & 0.045 \\
\hline & Avoid using electronic devices just before bed time & 0.873 & 0.396 & 4.853 & 2.394 & $1.101-5.206$ & 0.028 \\
\hline & Not drinking alcohol to induce sleep & 0.404 & 0.239 & 2.860 & 1.499 & $0.938-2.395$ & 0.091 \\
\hline & Not thinking about troubles in bed & 1.038 & 0.233 & 31.453 & 3.700 & $2.342-5.845$ & 0.000 \\
\hline & Keeping the bedroom quiet and comfortable & 0.781 & 0.264 & 8.778 & 2.184 & $1.303-3.663$ & 0.003 \\
\hline & Using a comfortable mattress and bedclothing & 0.721 & 0.224 & 10.391 & 2.056 & $1.326-3.187$ & 0.001 \\
\hline & Preventing an irregular getting up time (within $2 \mathrm{~h}$ ) & 0.649 & 0.227 & 8.190 & 1.913 & $1.227-2.983$ & 0.004 \\
\hline \multicolumn{8}{|c|}{ (B) Multiple logistic regression analysis } \\
\hline \multirow[t]{2}{*}{ Daily schedule } & Bed time & 0.108 & 0.137 & 0.623 & 1.114 & $0.852-1.456$ & 0.430 \\
\hline & Time in bed & -0.275 & 0.128 & 4.615 & 0.760 & $0.591-0.976$ & 0.032 \\
\hline Mood & Depressive mood & 1.497 & 0.319 & 21.976 & 4.468 & $2.390-8.355$ & 0.000 \\
\hline \multirow[t]{7}{*}{ Sleep hygiene } & Eating breakfast every morning & 0.431 & 0.284 & 2.308 & 1.539 & $0.882-2.685$ & 0.129 \\
\hline & Not going out to bright places after 21:00 & 0.088 & 0.300 & 0.087 & 1.092 & $0.607-1.965$ & 0.768 \\
\hline & Avoid using electronic devices just before bed time & 0.552 & 0.443 & 1.555 & 1.737 & $0.729-4.138$ & 0.212 \\
\hline & Not thinking about troubles in bed & 0.952 & 0.257 & 13.776 & 2.591 & $1.567-4.284$ & 0.000 \\
\hline & Keeping the bedroom quiet and comfortable & 0.343 & 0.312 & 1.210 & 1.409 & $0.765-2.597$ & 0.271 \\
\hline & Using a comfortable mattress and bedclothing & 0.128 & 0.269 & 0.226 & 1.137 & $0.670-1.927$ & 0.635 \\
\hline & Preventing an irregular getting up time (within $2 \mathrm{~h}$ ) & 0.188 & 0.269 & 0.486 & 1.207 & $0.712-2.046$ & 0.486 \\
\hline
\end{tabular}

good sleep quality [46]. Skipping breakfast may lead to the loss of these effects.

\section{Depressive Mood}

Hammond et al. reported that $26 \%$ of athletes showed self-reported mild to moderate symptoms of depression
[47]. In their study, they demonstrated that in elite athletes, negative changes in their performances were correlated with depression. Guilliver et al. examined 224 elite Australian athletes and reported that $27.2 \%$ of them displayed depressive symptoms [48]. Yang et al. examined 257 collegiate athletes and reported that $21 \%$ of their 
Table 7 The associations amongst sex, age, body mass index, experience of overseas trips, training-practice schedule, depressive mood and sleep habits, and poor sleep quality (PSQI global score > 5.5) in females

\begin{tabular}{|c|c|c|c|c|c|c|c|}
\hline & & $\beta$ & SE & Wald-square & Odds & $95 \% \mathrm{Cl}$ & $P$ value \\
\hline \multicolumn{8}{|c|}{ (A) Univariate logistic regression analysis } \\
\hline \multirow[t]{3}{*}{ General information } & Age & 0.024 & 0.023 & 1.131 & 1.024 & $0.980-1.070$ & 0.296 \\
\hline & Body mass index & 0.047 & 0.043 & 1.191 & 1.048 & $0.964-1.139$ & 0.878 \\
\hline & Frequency of overseas trips & 0.007 & 0.050 & 0.022 & 1.007 & $0.914-1.111$ & 0.882 \\
\hline \multirow[t]{7}{*}{ Daily schedule } & Earliest training-practice start time & -0.063 & 0.045 & 1.918 & 0.939 & $0.859-1.026$ & 0.166 \\
\hline & Latest training-practice end time & 0.012 & 0.056 & 0.050 & 1.013 & $0.908-1.129$ & 0.823 \\
\hline & Hours of training-practice per week & 0.006 & 0.009 & 0.458 & 1.006 & $0.988-1.025$ & 0.499 \\
\hline & Bed time & 0.141 & 0.125 & 1.280 & 1.151 & $0.902-1.470$ & 0.258 \\
\hline & Getting up time & -0.277 & 0.127 & 4.794 & 0.758 & $0.591-0.971$ & 0.029 \\
\hline & Time in bed & -0.378 & 0.120 & 9.895 & 0.685 & $0.542-0.867$ & 0.002 \\
\hline & Nap duration & 0.361 & 0.233 & 2.411 & 1.435 & $0.910-2.265$ & 0.121 \\
\hline \multirow[t]{4}{*}{ Clinical information } & Loud snoring & -0.024 & 0.251 & 0.009 & 0.976 & $0.597-1.596$ & 0.923 \\
\hline & Sleep apnea & 1.061 & 0.772 & 1.888 & 2.889 & $0.636-13.121$ & 0.169 \\
\hline & Legs twitching or jerking during sleep & 0.336 & 0.227 & 2.183 & 1.399 & $0.896-2.185$ & 0.140 \\
\hline & Disorientation or confusion during sleep & 0.316 & 0.350 & 0.814 & 1.371 & $0.691-2.723$ & 0.367 \\
\hline Mood & Depressive mood & 1.036 & 0.257 & 16.218 & 2.817 & $1.702-4.663$ & 0.000 \\
\hline \multirow[t]{10}{*}{ Sleep hygiene } & Being bathed in sunlight after getting up & 0.187 & 0.225 & 0.693 & 1.206 & $0.776-1.873$ & 0.405 \\
\hline & Eating breakfast every morning & 0.848 & 0.301 & 7.908 & 2.334 & $1.293-4.214$ & 0.005 \\
\hline & Not taking a nap after 15:00 & 0.343 & 0.224 & 2.342 & 1.409 & $0.908-2.186$ & 0.767 \\
\hline & Not going out to bright places after 21:00 & 0.086 & 0.224 & 0.147 & 1.090 & $0.703-1.689$ & 0.701 \\
\hline & Avoid using electronic devices just before bed time & 0.772 & 0.410 & 3.546 & 2.164 & $0.969-4.835$ & 0.060 \\
\hline & Not drinking alcohol to induce sleep & 1.024 & 0.329 & 9.677 & 2.784 & $1.461-5.308$ & 0.002 \\
\hline & Not thinking about troubles in bed & 0.880 & 0.235 & 13.963 & 2.410 & $1.519-3.823$ & 0.000 \\
\hline & Keeping the bedroom quiet and comfortable & 0.624 & 0.340 & 3.369 & 1.865 & $0.959-3.630$ & 0.066 \\
\hline & Using a comfortable mattress and bedclothing & 0.454 & 0.234 & 3.776 & 1.574 & $0.996-2.489$ & 0.052 \\
\hline & Preventing an irregular getting up time (within $2 \mathrm{~h}$ ) & 0.701 & 0.230 & 9.317 & 2.015 & $1.285-3.159$ & 0.002 \\
\hline \multicolumn{8}{|c|}{ (B) Multiple logistic regression analysis } \\
\hline \multirow[t]{2}{*}{ Daily schedule } & Getting up time & -0.353 & 0.169 & 4.390 & 0.702 & $0.505-0.977$ & 0.036 \\
\hline & Time in bed & -0.173 & 0.154 & 1.257 & 0.842 & $0.622-1.138$ & 0.262 \\
\hline Mood & Depressive mood & 0.922 & 0.277 & 11.092 & 2.515 & $1.462-4.329$ & 0.001 \\
\hline \multirow[t]{4}{*}{ Sleep hygiene } & Eating breakfast every morning & 0.622 & 0.336 & 3.429 & 1.862 & $0.964-3.595$ & 0.064 \\
\hline & Not drinking alcohol to induce sleep & 0.652 & 0.356 & 3.359 & 1.920 & $0.956-3.857$ & 0.067 \\
\hline & Not thinking about troubles in bed & 0.692 & 0.254 & 7.403 & 1.997 & $1.213-3.286$ & 0.007 \\
\hline & Preventing an irregular getting up time (within $2 \mathrm{~h}$ ) & 0.653 & 0.258 & 6.394 & 1.921 & $1.158-3.185$ & 0.011 \\
\hline
\end{tabular}

athletes showed depression, and anxiety and pain were related to that depression [49]. Other factors such as sports injuries, career termination, and performance outcomes that are below expectations are also risk factors of depression [50]. It is also well-known that a depressive mood is one of the symptoms of overtraining or overreaching [51]. Although it was unclear whether our athletes were suffering from overtraining or overreaching, such risks may arise during periods of high training loads [52].

Although sleep disturbance is known as one of the symptoms of depression, sleep deprivation lowers the psychological threshold for the perception of stress [53]. In addition, there is a report that individuals with short $(<7 \mathrm{~h} /$ night $)$ and long $(\geqq 9 \mathrm{~h} /$ night $)$ sleep durations show an increased genetic influence for depression [54]. 
Thus, sleep quantity and quality are associated with depression and vice versa.

\section{Thinking About Troubles in Bed}

Symptoms of chronic stress, burnout, anxiety, and nervousness are prevalent amongst athletes [55]. Erlacher et al. studied 632 German athletes and reported that $65.8 \%$ of them experienced poor sleep during nights before important competitions [13]. Romyn et al. demonstrated strong negative associations between state anxiety and sleep quality in athletes [56]. Kashani et al. reported a significant correlation between perceived stress and the PSQI global score [57]. In non-pharmacologic treatment of insomnia, Lande and Gragnani recommend trying to resolve problems prior to bedtime or to make resolution a priority the following day [58]. Siebern et al. recommends relaxation techniques including progressive muscle relaxation, deep breathing techniques, body scanning, and autogenic training [59].

\section{Other Factors}

Although the logistic regression analysis did not reveal a significant association with sleep quality, $40 \%$ of the athletes had been informed by someone about "snoring loudly" and/or "leg twitching or jerking during sleep" (Table 5). Similarly, Swinbourne et al. examined 175 athletes in New Zealand and demonstrated that 38\% of them were defined as snorers and $8 \%$ reported having apnoeic episodes [18]. Tuomilehto et al. examined 107 professional ice-hockey players and found that 14 of them had obstructive sleep apnoea [19]. In our studies, loud snoring and a long pause between breaths were widely distributed in many BMI categories, and higher percentages of athletes were found in larger BMI categories. Emsellem and Murtagh said that a BMI above $28.0 \mathrm{~kg} / \mathrm{m}^{2}$ and a neck circumference greater than $40.0 \mathrm{~cm}$ are risk factors for obstructive sleep apnoea syndrome [16]. However, this BMI criterion might be too high for the Japanese. Itasaka et al. divided 257 Japanese subjects into three groups: normal weight (BMI under $24.0 \mathrm{~kg} / \mathrm{m}^{2}$ ), mildly obese (BMI $24.0-26.4 \mathrm{~kg} / \mathrm{m}^{2}$ ), and obese (BMI $26.4 \mathrm{~kg} / \mathrm{m}^{2}$ or higher), and showed that the apnoea-hypopnea index, intraoesophageal pressure, and lowest oxygen saturation became significantly worse according to the degree of obesity [60]. In this study, the athletes with a BMI at or above $25 \mathrm{~kg} / \mathrm{m}^{2}$ showed a higher frequency of being informed about long pauses between breaths. However, some athletes with a BMI below $25 \mathrm{~kg} / \mathrm{m}^{2}$ were also similarly informed. Other factors, such as microgenia, retrognathia, rhinostenosis, and enlarged tonsils, should also be examined to identify causes of apnoea/hypopnea. Regarding leg twitching or jerking, there are both physiological and pathological causes. If the leg twitching or jerking is physiological and does not fragment sleep, treatment is rarely necessary [61]. For pathological forms, sleep-related movement disorders, such as periodic limb movement disorder and restless legs syndrome, may be related. A low ferritin level $(>50 \mu \mathrm{g} / \mathrm{L})$ is one of the risk factors of restless leg syndrome [62]. Koehler et al. reported that $31 \%$ of male athletes and $57 \%$ of female athletes showed serum ferritin levels below $35 \mu \mathrm{g} / \mathrm{L}$ [63]. Checking blood profiles might be recommended if sleep is disturbed by frequent limb movements. In a study on 107 professional ice hockey players, Tuomilehto et al. found 14 with obstructive sleep apnoea, 13 with insomnia, 4 with restless legs syndrome and periodic leg movements, 1 with parasomnia, and 1 with delayed sleep-wake syndrome [19]. We should keep in mind that factors not showing an association in our logistic analysis may also affect individual athlete's sleep quality.

\section{Sex Differences}

For both males and females, depressive mood and the hygiene-factor "not thinking about troubles in bed" were correlated with poor sleep quality (Tables 6 and 7). Time in bed for males and getting up time and the hygienefactor "preventing an irregular getting up time (within $2 \mathrm{~h}$ )" for females were also correlated with poor sleep quality. These results suggest that psychological factors and sleep schedules are common factors that affect poor sleep quality.

\section{Limitations}

Firstly, we investigated Japanese athletes' sleeping habits using a questionnaire and not by actual measurements. If applicable, it would be desirable to evaluate sleep schedules with equipment such as actigraphy $[2-4,8,9$, 11, 12]. Secondly, Samuels et al. developed a new athlete-specific sleep-screening questionnaire because they felt that the PSQI classified a higher than expected number of athletes as poor sleepers [20]. For example, $24.7 \%$ of males and $32.1 \%$ of females showed a PSQI global score above 5.5, whereas our PSQI subcategory scores indicated that the number of athletes with insomnia seems to be small. It is debatable whether the PSQI is the most suitable sleep-screening questionnaire for athletes. Thirdly, athletes younger than 20 years old were excluded from this study. Since many of them spend the daytime at high school or junior high school, their training schedules and sleeping habits may be different from those shown by our results. Fourthly, we could not evaluate athletes' performance in this research. Further studies are necessary to verify that an improvement in sleep leads to enhanced sport performance. 


\section{Conclusion}

In conclusion, 229 (28.0\%) athletes had a PSQI global score showing poor sleep quality. Compared to the results in a previous study [37], our results suggest that the prevalence of poor sleep quality in athletes is slightly lower than that in age-matched general populations. The multiple logistic analysis in our study revealed that poor sleep quality on the PSQI global score is related to five factors: "time in bed," "depressive mood," "eating breakfast every morning," "avoiding the use of electronic devices (PC, smartphone) just before bedtime," and "not thinking about troubles in bed." Forty percent of athletes reported they had been informed by someone about "snoring loudly" and/or "leg twitching or jerking during sleep," which would suggest that sleep quality would be poor; however, this finding was not significantly associated with poor sleep quality on the PSQI global score. In the medical check for athletes, it may be desirable to include screening for sleep disorders.

\section{Abbreviations}

BMI: Body mass index; ESS: Epworth Sleepiness Scale; PSQI: Pittsburgh Sleep Quality Index

\section{Acknowledgements}

We thank the Japanese Olympic Committee and the athletes who participated in this study. This study was carried out as part of the Research Projects of Japan Institute of Sports Sciences.

\section{Funding}

This study was partially supported by JSPS KAKENHI Grant Number 26350827.

\section{Availability of Data and Materials}

Not applicable.

\section{Authors' Contributions}

$\mathrm{MH}$ was involved in the design, data collection, analysis, and article writing. SU supervised the research design. YH managed the conduction of the research and revised the manuscript. All authors read and approved the final manuscript.

\section{Ethics Approval and Consent to Participate}

All procedures performed involving human participants were conducted in accordance with the ethical standards of the institutional and/or national research committee and with the 1964 Helsinki declaration and its later amendments or comparable ethical standards. Informed consent was obtained from all individual participants included in the study.

\section{Consent for Publication}

Consent to publish was obtained from all the participants.

\section{Competing Interests}

Masako Hoshikawa, Sunao Uchida, and Yuichi Hirano declare no conflicts of interest.

\section{Publisher's Note}

Springer Nature remains neutral with regard to jurisdictional claims in published maps and institutional affiliations.

\section{Author details}

'Department of Sport Research, Japan Institute of Sport Sciences, 3-15-1 Nishigaoka, Kita-ku, Tokyo 115-0056, Japan. ${ }^{2}$ Faculty of Sport Sciences, Waseda University, Mitakajima, Tokorozawa, Saitama, Japan. ${ }^{3}$ Faculty of Sports and Health Studies, Hosei University, 4342 Aihara-Cho, Machida, Tokyo 194-0298, Japan.
Received: 21 August 2017 Accepted: 22 January 2018

Published online: 26 February 2018

\section{References}

1. Robson-Ansley P, Gleeson M, Ansley L. Fatigue management in the preparation of Olympic athletes. J Sports Sci. 2009;27:1409-20.

2. Leeder J, Glaister M, Pizzoferro K, Dawson J, Pedlar C. Sleep duration and quality in elite athletes measured using wristwatch actigraphy. J Sports Sci. 2012:30(6):541-5.

3. Sargent C, Halson S, Roach GD. Sleep or swim? Early-morning training severely restricts the amount of sleep obtained by elite swimmers. Eur J Sports Sci. 2014;14(S1):S310-5.

4. Sargent C, Lastella M, Halson SL, Roach GD. The impact of training schedules on the sleep and fatigue of elite athletes. Chronobiol Int. 2014;31:1160-8.

5. Shapiro CM, Bortz R, Mitchell D. Slow-wave sleep: a recovery period after exercise. Science. 1981;214(11):1253-4.

6. Taylor SR, Rogers GG, Driver HS. Effects of training volume on sleep, psychological, and selected physiological profiles of profiles of elite female swimmers. Med Sci Sports Exerc. 1997;29(5):688-93.

7. Hague JFE, Gilbert SS, Burgess HJ, Ferguson SA, Dawson D. A sedentary day: effects on subsequent sleep and body temperatures in trained athletes. Physiol Behav. 2003;78:261-7.

8. Kolling S, Wiewelhove T, Raeder C, Endler S, Ferrauti A, Meyer T, et al. Sleep monitoring of a six-day macrocycle in strength and high-intensity training. Eur J Sport Sci. 2016;16(5):507-15

9. Killer SC, Svendsen IS, Jeukendrup AE, Gleeson M. Evidence of disturbed sleep and mood state in well-trained athletes during short-term intensified training with and without a high carbohydrate nutritional intervention. J Sports Sci. 2017;35(14):1402-10.

10. Fullagar HHK, Skorski S, Duffield R, Julian R, Bartlett J, Meyer T. Impaired sleep and recovery after night matches in elite football players. J Sports Sci. 2016;34(14):1333-9.

11. Staunton C, Gordon B, Custovic E, Stanger J, Kingsley M. Sleep patterns and match performance in elite Australian basketball players. J Sci Med Sport. https://doi.org/10.1016/j.jsams.2016.11.016.

12. Lastella M, Roach GD, Halson SL, Martin DT, West NP, Sargent C. Sleep/wake behavior of endurance cyclists before and during competition. J Sports Sci. 2015;33(3):293-9.

13. Erlacher D, Ehrlenspiel F, Adegbesan OA, El-Din HG. Sleep habits in German athletes before important competitions or games. J Sports Sci. 2011;29(8):859-66.

14. Juliff LE, Halson SL, Peiffer JJ. Understanding sleep disturbance in athletes prior to important competitions. J Sci Med Sport 2015;18(1):13-18.

15. Lastella M, Lovell GP, Sargent C. Athletes' precompetitive sleep behavior and its relationship with subsequent precompetitive mood and performance. Eur J Sport Sci. 2014;14(S1):S123-30.

16. Emsellem HA, Murtagh KE. Sleep apnea and sports performance. Clin Sports Med. 2005:24:329-41.

17. Rice TB, Dunn RE, Lincoln AE, Tucker AM, Vogel RA, Heyer RA, et al. Sleepdisordered breathing in the national football league. Sleep. 2010;33(6):819-24.

18. Swinbourne R, Gill N, Vaile J, Smart D. Prevalence of poor sleep quality, sleepiness and obstructive sleep apnoea risk factors in athletes. Eur J Sport Sci. 2016;16(7):850-8.

19. Tuomilehto $H$, Vuorinen VP, Penttilä E, Kivimäki M, Vuorenmaa M, Venojärvi $M$, et al. Sleep of professional athletes: underexploited potential to improve health and performance. J Sports Sci. 2017;35(7): 704-10.

20. Samuels C, James L, Lawson D, Meeuwisse W. The athlete sleep screening questionnaire: a new tool for assessing and managing sleep in elite athletes. Br J Sport Med. 2016;50(7):418-22.

21. Munezawa T, Kaneita Y, Osaki Y, Kanda H, Minowa M, Suzuki K, et al. The association between use of mobile phones after lights out and sleep disturbances among Japanese adolescents: a nationwide cross-sectional survey. Sleep. 2011;34(8):1013-20.

22. Chang AM, Aeschbach D, Duffy JF, Czeisler CA. Evening use of lightemitting eReaders negatively affects sleep, circadian timing, and nextmorning alertness. Proc Natl Acad Sci U S A. 2015;112(4):1232-7.

23. White AG, Biboltz W, Igou F. Mobile phone use and sleep quality and length in college students. Int J Humanities Soc Sci. 2011;1(18):51-8.

24. Mastin DF, Bryson J, Corwyn R. Assessment of sleep hygiene using the Sleep Hygiene Index. J Behav Med. 2006;29(3):223-7. 
25. Kang JH, Chen SC. Effects of irregular bedtime schedule on sleep quality, daytime sleepiness, and fatigue among university students in Taiwan. BMC Public Health. 2009;9:248. https://www.ncbi.n/m.nih.gov/pmc/articles/ PMC2718885/. accessed 31 July 2017

26. Buysse DJ, Reynolds CF 3rd, Monk TH, Berman SR, Kupfer DJ. The Pittsburgh sleep quality index: a new instrument for psychiatric practice and research. Psychiatry Res. 1989;28(2):193-213.

27. Fietze I, Strauch J, Holzhausen M, Glos M, Theobald C, Lehnkerning H, et al. Sleep quality in professional ballet dancers. Chronobiol Internat. 2009;26(6):1249-62.

28. Knufinke M, Nieuwenhuys A, SAE G, AML C, MA K. Self reported sleep quantity, quality and sleep hygiene in elite athletes. J Sleep Res. 2017; http://onlinelibrary.wiley.com/doi/10.1111/jsr.12509/epdf. accessed 31 July 2017

29. Hoshikawa M, Uchida S, Fujita Y. Questionnaire study of the sleeping habits of elite Japanese athletes. Jpn J Clin Sports Med. 2015;23(1):74-87.

30. Doi Y, Minowa M, Uchiyama M, Okawa M. Development of the Pittsburgh sleep quality index Japanese version. Jpn J Psychiatry Treat. 1998;13(6):755-63.

31. Takegami M, Suzukamo Y, Wakita T, Noguchi H, Chin K, Kadotani H, et al. Development of a Japanese version of the Epworth Sleepiness Scale (JESS) based on item response theory. Sleep Med. 2009;10:556-65.

32. Whooley MA, Avins AL, Miranda J, Miranda J, Browner WS. Case finding instruments for depression. Two questions are good as many. J Gen Intern Med. 1997;12:439-45

33. Doi Y, Minowa M, Uchiyama M, Okawa M, Kim K, Shibui K, et al. Psychometric assessment of subjective sleep quality using the Japanese version of the Pittsburgh Sleep quality index (PSQI-J) in psychiatric disordered and control subjects. Psychiatry Res. 2000:97(2):165-72.

34. Suzuki T, Nobata R, Kim N, Hane Y, Narita T, Iwata N, et al. Evaluation of questionnaire (Two-question case-finding instrument and Beck depression inventory) as a tool for screening and intervention of depression in work place. Seishin Igaku (Clinical Psychiatry). 2003;45:699-708.

35. Tamura N, Tanaka H. Effects of sleep education with self-help treatment for elementary schoolchild with nocturnal lifestyle. Sleep Biol Rhythms. 2014;12:169-79.

36. Doi Y, Minowa M, Uchiyama M, Okawa M. Subjective sleep quality and sleep problems in the general Japanese adult population. Psychiat and Clin Neurosci. 2001;55:213-5.

37. Doi Y, Minowa M. Gender differences in excessive daytime sleepiness among Japanese workers. Soc Sci Med. 2003;56(4):883-94.

38. Sekine C, Watanabe Y, Hayashida M. No more decline in sleeping time, more time now spent on necessary activities from the 2015 NHK Japanese time use survey. The NHK monthly report on broadcast research, 2016 May, 2-27. http://www.nhk.or.jp/bunken/english/reports/pdf/report_16071301.pdf 8. accessed on 1 May 2017.

39. Mah CD, Mah KE, Kezirian EJ, Dement WC. The effects of sleep extension on the athletic performance of collegiate basketball players. Sleep. 2011;34(7):943-50.

40. Samuels $\mathrm{CH}$, Alxander BN. Sleep, recovery, and human performance. A comprehensive strategy for long-term athlete development. Sport for life. http://www.swimsask.ca/pdf/Sleep-and-Recovery.pdf. accessed 1 May 2017.

41. Bompa TO, Haff GG. Periodization: theory and methocology of training. 5th ed. Champaign: Human Kinetics Pub; 2009. p. 97-122.

42. Rountree $\mathrm{S}$. The athlete's recovery: rest, relax, and restore for peak performance. Boulder: Velopress; 2011.

43. Ministry of Post and Telcomminications (Japan). White paper communications in Japan 1998. Gyosei; 1998. p. 10-6. (in Japanese). http:// www.soumu.go.jp/johotsusintokei/whitepaper/ja/h10/pdf/index.html. accessed on 1 May 2017

44. Wang L, Qin P, Zhao Y, Duan S, Zhang Q, Liu Y, et al. Prevalence and risk factors of poor sleep quality among inner Mongolia medical university students: a cross-sectional survey. Psychiatry Res. 2016;244:243-8.

45. Hirao A, Nagahama H, Tsuboi T, Hirao M, Tahara Y, Shibata S. Combination of starvation interval and food volume determines the phase of liver circadian rhythm in Per2: Luc knock-in mice under two meals per day feeding. Am J Physiol Gastrointest Liver Physiol. 2010;299:G1045-53.

46. Halson SI. Sleep in elite athletes and nutritional interventions to enhance sleep. Sports Med. 2014;44(Suppl):S13-23.

47. Hammond T, Gialloreto C, Kubas H, Hap Davis H IV. The prevalence of failure-based depression among elite athletes. Clin J Sports Med. 2013; 23:273-7.

48. Guilliver A, Griffiths K, Mackinnon A, Batterham PJ, Stanimirovic R. The mental health of Australian elite athletes. J Sci Med Sport. 2015;18(3):255-61.
49. Yang J, Peek-Asa C, Corlette JD, Cheng G, Foster DT, Albright J. Prevalence of and risk factors associated with symptoms of depression in competitive collegiate student athletes. Clin J Sports Med. 2007;17:481-7.

50. Wolanin A, Gross M, Hong E. Depression in athletes: prevalence and risk factors. Cur Sports Med Reports. 2015;14(1):56-60.

51. Urhausen A, Kindermann W. Diagnosis of overtraining. What tools do we have? Sports Med. 2002;32(2):95-102.

52. Hausswrth C, Louis J, Aubry A, Bonnet G, Duffield R, Meur YL. Evidence disturbed sleep and increased illness in overreached endurance athletes. Med Sci Sports Exerc. 2014;46(5):1036-45.

53. Minkel JD, Banks S, Htaik O, Moreta MC, Jones CW, McGlinchey EL, et al. Sleep deprivation and stressors: evidence for elevated negative affect in response to mild stressors when sleep deprived. Emotion. 2012;12(5):1015-20.

54. Watson NF, Harden KP, Buchwald D, Vitello MV, Pack Al, Strachan E, et al. Sleep duration and depressive symptoms: a gene-environment interaction. Sleep. 2014;37:351-8.

55. Demarzo MMP, Stein PK. Mental stress and exercise training response: stress-sleep connection may be involved. Front Physiol. 2012;3:51. https:// doi.org/10.3389/fphys.2012.00051. accessed 2 May 2017

56. Romyn G, Robey E, Dimmock JA, Halson SL, Peeling P. Sleep, anxiety, and electronic device use by athletes in the training and competition environment. Eur J Sports Sci. 2016:16(3):301-8.

57. Kashani M, Eliasson A, Vernalis M. Perceived stress correlates with disturbed sleep: a link connecting stress and cardiovascular disease. Stress. 2012;15(1):45-51

58. Lande RG, Gragnani C. Nonpharmacologic approaches to the management of insomnia. J Am Osteopath Assoc. 2010;110(12):695-701.

59. Seibern AT, Suh S, Nowakowski S. Non-pharmacological treatment of insomnia. Neurotherapeutics. 2012;9:717-27.

60. Itasaka Y, Miyazaki S, Ishikawa K, Togawa K. The influence of sleep position and obesity on sleep apnea. Psychirat Clin Neurosci. 2000;54:340-1.

61. Iber C, Ancoli-Israel S, Chesson A, Quan SF, for the American Academy of Sleep Medicine. The AASM manual for the scoring of sleep and associated events: rules, terminology and technical specifications. 1st ed. Westcher: American Academy of Sleep Medicine; 2007. p. 41-3.

62. O'Keeffe ST. Iron deficiency with normal ferritin levels in restless legs syndrome. Sleep Med. 2005:6:281-2.

63. Koehler K, Braun H, Achtzehn S, Hildebrand U, Predel HG, Schänzer W. Iron status in elite young athletes: gender-dependent influences of diet and exercise. Eur J Appl Physiol. 2012;112:513-23.

\section{Submit your manuscript to a SpringerOpen ${ }^{\circ}$ journal and benefit from:}

- Convenient online submission

- Rigorous peer review

- Open access: articles freely available online

- High visibility within the field

Retaining the copyright to your article

Submit your next manuscript at $>$ springeropen.com 